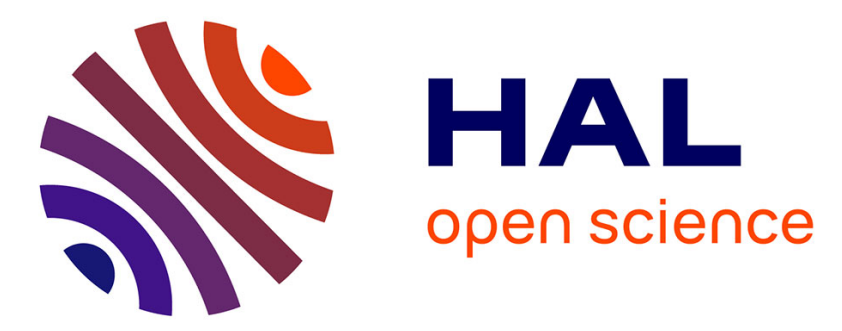

\title{
Characterization of Poly(styrenesulfonate) at Minimum Ionic Strength by Electric and Magnetic Birefringence Experiments
}

\author{
C. Johner, H. Kramer, C. Martin, J. Biegel, R. Deike, R. Weber
}

\section{- To cite this version:}

C. Johner, H. Kramer, C. Martin, J. Biegel, R. Deike, et al.. Characterization of Poly(styrenesulfonate) at Minimum Ionic Strength by Electric and Magnetic Birefringence Experiments. Journal de Physique II, 1995, 5 (5), pp.721-732. 10.1051/jp2:1995160 • jpa-00248195

\section{HAL Id: jpa-00248195 https://hal.science/jpa-00248195}

Submitted on 1 Jan 1995

HAL is a multi-disciplinary open access archive for the deposit and dissemination of scientific research documents, whether they are published or not. The documents may come from teaching and research institutions in France or abroad, or from public or private research centers.
L'archive ouverte pluridisciplinaire HAL, est destinée au dépôt et à la diffusion de documents scientifiques de niveau recherche, publiés ou non, émanant des établissements d'enseignement et de recherche français ou étrangers, des laboratoires publics ou privés. 
Classification

Physics Abstracts

$78.20 \mathrm{~F}-78.20 \mathrm{~L}-8270 \mathrm{D}$

\title{
Characterization of Poly(styrenesulfonate) at Minimum Ionic Strength by Electric and Magnetic Birefringence Experiments
}

\author{
C. Johner $\left({ }^{1, *}\right)$, H. Kramer $\left({ }^{2}\right)$, C. Martin $\left({ }^{1}\right)$, J. Biegel $\left({ }^{1}\right)$, R. Deike $\left({ }^{1}\right)$ and R. Weber $\left({ }^{1}\right)$ \\ ( $\left.{ }^{1}\right)$ Fakultät für Physik, Universitat Konstanz, 78434 Konstanz, Germany \\ $\left({ }^{2}\right)$ Max-Planck-Institut für Festkorperforschung, Hochfeld - Magnetlabor, 38042 Grenoble, \\ France
}

(Received 19 September 1994, revised 17 November 1994, accepted 18 January 1995)

\begin{abstract}
Results of birefringence experiments on aqueous solutions of charged poly(styrenesulfonate) (PSS) with different molecular weights between $10^{5}$ and $1.1 \times 10^{6} \mathrm{~g} / \mathrm{mol}$ in external electric and magnetic fields are presented. Most of our studies are carried out on solutions of minimum ionic strength (down to $\approx 10^{-6} \mathrm{M}$ ), under conditions where the particles are surrounded by extended counterion clouds. The PSS particles can be nearly completely oriented in high electric fields $\left(>10^{5} \mathrm{~V} / \mathrm{m}\right)$ and the saturation value of the birefringence is obtained. In low electric fields a Kerr behavior is found and we are able to determine the electric anisotropy $\Delta \alpha_{\mathrm{el}}\left(=\alpha_{\mathrm{el}, \|\}}-\alpha_{\mathrm{el}, \perp}\right)$ of a single particle caused by the ansotropic polarization of the counterion cloud. At low particle concentrations $c$, this cloud (respectively the electric anisotropy) decreases like $c^{-1 / 2}$ with increasing concentration Rising this concentration once more leads to a decrease of the Kerr constant $\left(k \propto \Delta \alpha_{\mathrm{el}} \cdot l_{\mathrm{p}}\right.$, where $l_{\mathrm{p}}$ is the persistence length characterizing flexible polymers) faster than $c^{-1 / 2}$ pointing out a starting coiling expressed by a lowering of the persistence length. In the electric birefringence experıment we are limited to particle concentrations between $5 \times 10^{-4}$ and $5 \mathrm{mg} / \mathrm{ml}$ wherefore we complemented our studies by high magnetic field experiments $(0<B<168 \mathrm{~T})$ at higher concentrations $(10<c<75 \mathrm{mg} / \mathrm{ml})$ The mechanism orientıng PSS particles in magnetic fields is much weaker than that in electric fields. Therefore no full alignment of our polyelectrolytes is possible, all measurements are done in the Cotton-Mouton regime. This is the first investigation of the persistence length of poly(styrenesulfonate) at minimum ionic strength over a wide concentration regime.
\end{abstract}

\section{Introduction}

Colloidal solutions are often used as simple model systems for atomic diffusion and crystallization processes. The structure of solutions of charged spheres [1] and rigid rods like TMV [2] or fd - viruses [3] were theoretically and experimentally investigated and understood. Uncharged flexible polymers can be well described [4], for example as Gaussian coils. Meanwhile, there are theoretical and experimental results on charged flexible polyelectrolytes that are partially

$\left({ }^{*}\right)$ Author to whom correspondence should be addressed 
in contradiction to each other. This may be caused by different salt concentrations of the solutions in these various experiments. The often used description "without added salt" is insufficient to characterize the ionic strength wherefore we choose a special experimental set-up and reached the minimum ionic strength (down to $\approx 10^{-6} \mathrm{M}$ ). We will show that the influence of the ionic strength on the particle properties like flexibility is crucial. This minimum ionic strength distinguishes our work from those of Weill and Maret [5] and Krämer et al. [6]. A strong electrostatic interaction between the charged monomers leads to a stiffening of the chain, respectively to an increase of the electric part of the persistence length $l_{\mathrm{e}}$. The total persistence length $l_{\mathrm{p}}$ is the sum of this and an intrinsic part $l_{1}(1.2 \mathrm{~nm}$ for PSS) [7]:

$$
l_{\mathrm{p}}=l_{\mathrm{i}}+l_{\mathrm{e}}
$$

We are especially interested in this (concentration-dependent) persistence length describing the flexibility of the polymers. An infinite persistence length means an infinitely rigid rod while gaussian coils are represented by a vanishing persistence length.

Our system, poly(styrenesulfonate), is a polyelectrolyte consisting of a number $N$ of charged monomers each with a molecular weight $m_{0}=206 \mathrm{~g} / \mathrm{mol}$ and a length of $a=0.25 \mathrm{~nm}$, and carrying an aromatic ring which determines the optical anisotropy and the anisotropy of the diamagnetic susceptibility of the particle. In aqueous solutions the monomers are negatively charged. We examine PSS particles with molecular weights between $10^{5}$ and $1.1 \times 10^{6} \mathrm{~g} / \mathrm{mol}$. This corresponds to contour lengths $l_{c}(=N \times$ a) between 120 and $1350 \mathrm{~nm}$ and extends the range both of molecular weights and the concentrations examined by Weill and Maret [5] $(\mathrm{MW}=15000,40000$ and $140000 \mathrm{~g} / \mathrm{mol}, c \leq 20 \mathrm{mg} / \mathrm{ml})$ with a magnetic birefringence set-up. Kikuchi et al. [8] measured the electric birefrngence of the solution as a function of the applied electric field and determined the saturation value. Even at very low electric field strength they find no anomalous birefringence in contrast to other authors $[6,9,10]$. As discussed in a previous paper [11] the anomalous birefringence - an effect of particles which are oriented perpendicular to the applied external field - is caused by a dominating particle - particle interaction, and can be avoided by using high frequency pulses. The disappearance of anomalous signals at higher frequencies can be explained by the frequency dependencies of the electric polarizabilities parallel $\alpha_{\mathrm{el}, \|}$ and perpendicular $\alpha_{\mathrm{el}, \perp}$ to the particle length axis (for a more detailed description see reference [12]).

We are able to perform electric birefringence measurements at concentrations which are partially over one order of magnitude smaller $(c>0.0005 \mathrm{mg} / \mathrm{ml})$ than those of other authors and so to examine single, only weakly interacting particles. Furthermore, we measure the saturation value of the birefringence $\Delta n_{\text {sat }} / c$ which is necessary to interpret the birefringence data in a correct way. Kikuchi and Yoshioka give a saturation value of about $\Delta n_{\text {sat }} / c=$ $5.5 \times 10^{-5} \mathrm{ml} / \mathrm{mg}$ (measured at a wavelength of the incident light $\lambda=546 \mathrm{~nm}$ ), Tricot and Houssier [13] found $2.0<\Delta n_{\text {sat }} / c<3.0 \times 10^{-5} \mathrm{ml} / \mathrm{mg}(\lambda=550 \mathrm{~nm})$. Finally the saturation value obtained by Krämer (Fig. 5.7a of Ref. [6]), can be estimated to be about $10^{-5} \mathrm{ml} / \mathrm{mg}$ $(\lambda=633 \mathrm{~nm})$.

\section{Theory}

Solutions of PSS particles are optically isotropic if no external field is applied because the particles are isotropically oriented. However it is possible to orient them by an electric or a magnetic field The solution becomes optically anısotropic and therefore birefringent. For small applied fields the birefringence $\Delta n$ is proportional to the square of the field strength. This behavior is called the Kerr law in the case of electric fields and Cotton-Mouton law in 
the case of external magnetic fields:

$$
\begin{gathered}
\Delta n=k \lambda E^{2} \\
\Delta n=C_{\mathrm{M}} \lambda B^{2}
\end{gathered}
$$

where $\lambda$ is the wavelength of the incident light and $k$ and $C_{\mathrm{M}}$ are the Kerr respectively the Cotton-Mouton constants. In the case of rigid rods $C_{M}$ and the Kerr constant can be calculated [14]:

$$
\begin{gathered}
k=\frac{\Delta n_{\mathrm{sat}} \cdot \Delta \alpha_{\mathrm{el}}}{15 \lambda k_{\mathrm{B}} T} \\
C_{\mathrm{M}}=\frac{\Delta n_{\mathrm{sat}} \cdot \Delta \chi}{15 \mu_{0} \lambda k_{\mathrm{B}} T}
\end{gathered}
$$

where $k_{\mathrm{B}} T$ is the thermal energy, $\mu_{0}$ the permeability and $\Delta \chi=\chi_{\|}-\chi_{\perp}$ is the anisotropy of the diamagnetic susceptibility of one particle. The saturation value of the birefringence $\Delta n_{\text {sat }}$ which is reached for infinitely high fields is directly proportional to the optical anisotropy $\Delta \alpha_{0}$ $\left(=\alpha_{0, \|}-\alpha_{0, \perp)}\right.$ of one particle. The local optical field is not clear, therefore field corrections are frequently ignored for macromolecular solutions and hence:

$$
\Delta n_{\mathrm{sat}}=\frac{c N_{\mathrm{a}}}{2 \varepsilon_{0} n m_{0}} \cdot \frac{\Delta \alpha_{0}}{N}
$$

where $c$ is the particle concentration, $n$ the refractive index, $N_{\mathrm{a}}$ Avogadro's number and $\varepsilon_{0}$ the permittivity of vacuum.

For flexible rods the situation becomes somewhat more complicate, but a description of wormlike chains already exists $[15,16]$ and permits a calculation of the Kerr and the CottonMouton constants.

$$
\begin{gathered}
\frac{\Delta n}{c \lambda E^{2}}=\frac{k}{c}=\frac{N_{\mathrm{a}} \frac{\Delta \alpha_{0}}{N} \frac{\Delta \alpha_{\mathrm{el}}}{N}}{45 \varepsilon_{0} n \lambda k_{\mathrm{B}} T a m_{0}} \cdot l_{\mathrm{p}} \cdot\left[1-\frac{l_{\mathrm{p}}}{3 l_{\mathrm{c}}} \cdot\left(1-\exp \left(-\frac{3 l_{\mathrm{c}}}{l_{\mathrm{p}}}\right)\right)\right] \\
\frac{\Delta \mathrm{n}}{c \lambda B^{2}}=\frac{C_{\mathrm{M}}}{c}=\frac{N_{\mathrm{a}} \frac{\Delta \alpha_{0}}{N} \frac{\Delta x}{N}}{45 \varepsilon_{0} \mu_{0} n \lambda k_{\mathrm{B}} T a m_{0}} \cdot l_{\mathrm{p}} \cdot\left[1-\frac{l_{\mathrm{p}}}{3 l_{\mathrm{c}}} \cdot\left(1-\exp \left(-\frac{3 l_{\mathrm{c}}}{l_{\mathrm{p}}}\right)\right)\right]
\end{gathered}
$$

Both the Kerr and the Cotton-Mouton constants depend on the persistence length $l_{\mathrm{p}}$. The formulae $(5 \mathrm{a}, \mathrm{b})$ are still vald for relatively stiff rods, for example for DNA with persistence lengths of several hundred nanometers [15]. Equation (5b) has been developed in order to calculate the persistence length by a known Cotton-Mouton constant. The treatment of the electric and magnetic birefringence on the equal footing as shown in equations $(5 a, b)$ is not $a b$ initio justified: $\Delta \chi / N$ is given by the intrinsic structure of the particle, whereas the electric polarizability $\Delta \alpha_{\text {el }}$ is an ionic polarizability determined by the diffuse counterion cloud. To calculate the persistence length $l_{\mathrm{p}}$ we need a corresponding quantity namely $\Delta \alpha_{\mathrm{el}} / N$. Of course the quantity $\Delta \alpha_{\mathrm{el}} / N$ is not a local property. It has no physical meaning and must be determined for every polyelectrolyte length. Therefore, the persistence lengths calculated by formula (5a) have to be considered as an estimation, strictly speaking as a lower bound, because $\Delta \alpha_{\text {el }} / N$ can not be treated by an additivity scheme. The quantity $\Delta \alpha_{\text {el }}$ of one monomer times the monomer number $N$ is expected to be smaller than $\Delta \alpha_{\mathrm{el}}$ of the whole chain. This assumption leads, as we will see, to reasonable values of the persistence length. 


\section{Experimental Section}

3.1. MATERIALS. - The sodium salts of poly(styrenesulfonate) were purchased from Polyscience and are marked by a degree of sulfonation $>90 \%$ and a narrow molecular weight distribution $\left(M_{\mathrm{w}} / M_{\mathrm{n}} \leq 1.1\right)$. They are especially designed for GPC calibration in aqueous media. In order to obtain polyelectrolytes with various contour length $l_{\mathrm{c}}$, we used five different molecular weights: $\mathrm{MW100}=1.0 \times 10^{5} \mathrm{~g} / \mathrm{mol}\left(l_{\mathrm{c}}=121 \mathrm{~nm}\right), \mathrm{MW} 200=2.0 \times 10^{5} \mathrm{~g} / \mathrm{mol}\left(l_{\mathrm{c}}=243 \mathrm{~nm}\right)$, MW350 $=3.5 \times 10^{5} \mathrm{~g} / \mathrm{mol}\left(l_{\mathrm{c}}=424 \mathrm{~nm}\right)$, MW780 $=7.8 \times 10^{5} \mathrm{~g} / \mathrm{mol}\left(l_{\mathrm{c}}=946 \mathrm{~nm}\right)$ and MW1132 $=1.13 \times 10^{6} \mathrm{~g} / \mathrm{mol}\left(l_{\mathrm{c}}=1373 \mathrm{~nm}\right)$. First, for each molecular weight a stock solution of either $1 \mathrm{mg} / \mathrm{ml}$ or $10 \mathrm{mg} / \mathrm{ml}$ or $75 \mathrm{mg} / \mathrm{ml}$ was prepared by dissolving the carefully weighted salt in highly purified and deionized water $(R>18 \mathrm{M} \Omega$ ) and checked by an absorption measurement (using a Beckmann spectrometer DU-64, Darmstadt, Germany). The desired concentrations were obtained by dilution.

3.2. Tube Pump System. - In order to reach minimum ionic strength we used a tube pump system, which is a closed circuit including the birefringence cell and a mixed-bed-ion exchange resin. The solutions are pumped through this circuit and the conductivity is always checked to proof that all measurements are performed at minimum ionic strength $[17,18]$. In a good approximation no small ions except $\mathrm{H}^{+}$and $\mathrm{OH}^{-}$are left in the solution, therefore the minimum ionic strength only depends on the particle concentration. No destruction of the PSS particles due to the experimental setup can be observed, neither in experiments which determine the rotational diffusion constant [11] nor in absorption measurements.

3 3. Electric Birefringence - The electric birefringence apparatus is the same commercial instrument (spectrometer DB10. Suck, Siegen, Germany) as used in our recent publication $[11,19]$ and is very similar to that described elsewhere [14]. The birefringence of the solution was measured in a quartz-cell (length $=5 \mathrm{~cm}$ ) at a wavelength of $632.8 \mathrm{~nm}$ at $20 \pm 0.1^{\circ} \mathrm{C}$. A more detailed description of the procedure is given in reference [20]

3.4. Magnetic Birefringence. - All magnetic birefringence experiments were performed at the High Magnetic Field Laboratory in a bitter-type magnet, which has a small radial bore. Again we measured at a wavelength of $632.8 \mathrm{~nm}$ at $20 \pm 01^{\circ} \mathrm{C}$; the length of the quartz-cells containing the solution was $3 \mathrm{~cm}$. The field was swept to the maximum field $(B=16.8 \mathrm{~T})$ within $250 \mathrm{~s}$ then swept down to $B=0$ in the same time while the birefringence was measured with a very high sensitivity (resolution $\Delta n \approx 10^{-9}$ ) using a combined photoelastic modulation and compensation technique which is described elsewhere [20]

\section{Results and Discussion}

4.1. Electric Birefringence Measurements. - As a first part we examined the saturation value of the electric birefringence for MW220, MW350 and MW1132 at different concentrations (Fig. 1). This value is needed to calculate the optical anisotropies (Eq. (4)) and by that the electric respectively the magnetic anisotropies (Eqs. $(3 \mathrm{a}+\mathrm{b})$ ) and the persistence length (Eqs. $(5 \mathrm{a}+\mathrm{b}))$. In order to minimize any kind of stripping of the counterion cloud in high electric fields, leading to a reduced $\Delta \alpha_{\text {el }}$ and a not complete orientation of the rods, as described by Oppermann [21], we used $50 \mathrm{kHz}$ pulsed square wave electric fields. In accordance with Oppermann this "stripping effect" is found maunly for long chains (molecular weight $>10^{6} \mathrm{~g} / \mathrm{mol}$ ) wherefore measuring $\Delta n_{\text {sat }}$ in DC fields leads for the shorter chains (MW220 and MW350) to the same results within the experimental error. The pulse lengths were chosen 


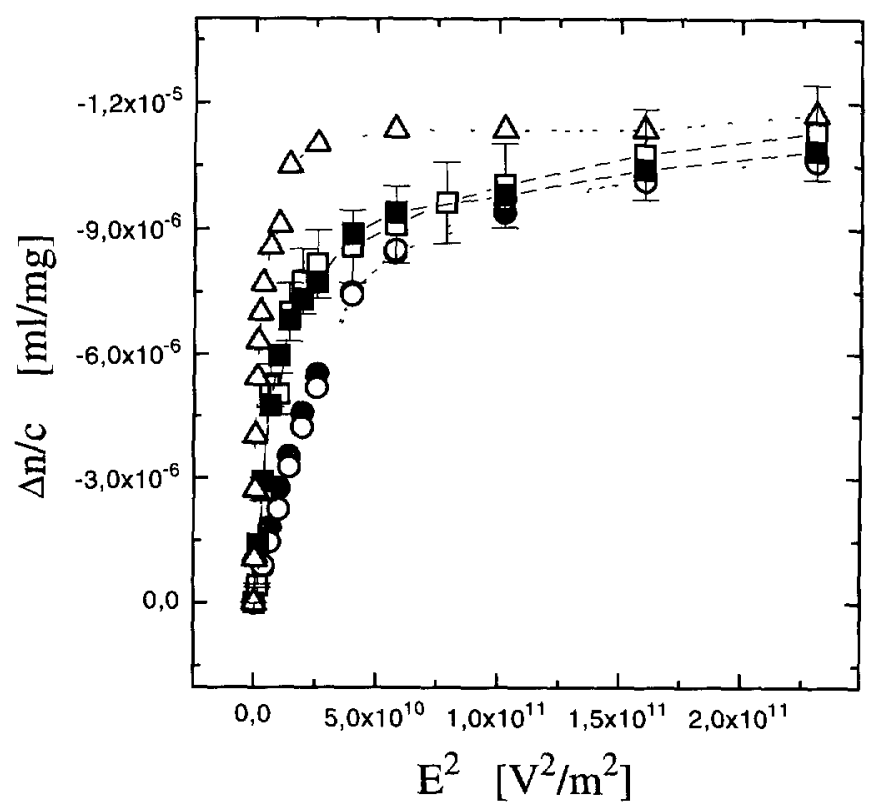

Fig. 1 - The electric birefringence signal of different PSS solutions, MW220 $(c=0.04 \mathrm{mg} / \mathrm{ml}$ $(\bullet), c=0.06 \mathrm{mg} / \mathrm{ml}(\mathrm{O})), \mathrm{MW} 350(\mathrm{c}=003 \mathrm{mg} / \mathrm{ml}(\square), c=0.06 \mathrm{mg} / \mathrm{ml}(\mathbf{\square}))$ and MW1132 $(c=0.08 \mathrm{mg} / \mathrm{ml}(\Delta))$ versus the square of the applied electric field strength. A $50 \mathrm{kHz}$ pulsed square wave electric field is used.

in a way that the maximum of the birefringence signal was achieved. The saturation is nearly reached at an electric field strength of $4.8 \times 10^{5} \mathrm{~V} / \mathrm{m}$.

We find $\Delta n_{\text {sat }} / c=-(1.2 \pm 0.1) \times 10^{-5} \mathrm{ml} / \mathrm{mg}$, independent of the concentration within experimental error. At low electric field strengths a distinct molecular weight dependence can be observed as the birefringence signal is proportional to $\Delta \alpha_{\text {el }}$ (Eqs. $(2 a+3 a)$ ). At very high electric field strength the saturation value only depends on the optical anisotropy $\Delta \alpha_{0} / N$ which is calculated to be $(1.0 \pm 0.08) \times 10^{-40} \mathrm{Fm}^{2}$ (Eq. (4)). Obviously $\Delta \alpha_{0} / N$ is not a function of the molecular weight respectively the particle contour length. Our saturation value is about 4 times smaller than that measured by Kikuchi et al. [8]. We cannot explain this contradiction, which is possibly caused by a higher ionic strength: though Kikuchi added no salt, he observed no anomalous signals. One should mention that all, the optical $\left(\Delta \alpha_{0} / N\right)$ and the magnetic $(\Delta \chi / N)$ anisotropy and the persistence length $l_{\mathrm{p}}$ calculated by Weill and Maret are based on this value. Nevertheless our value lies between those measured by Tricot et al. [13] and Krämer et al [6]. Also in contrast to the results of Kikuchi we can reach the Kerr law region even for very small concentrations (Fig. 2).

As well known from rigid rods [22] the electric birefringence in the Kerr regime and the specific Kerr constants, respectively, $k_{\mathrm{sp}}=k / c$ are concentration-dependent (Fig. 2). Kramer finds [12] $k$ and $k_{\text {sp }}$ respectively to be proportional to $c^{-1 / 2}$. We observe the same behavior (inlay of Fig. 2). With increasing concentration the ionic strength increases, too, wherefore the surrounding ion cloud of counterions, which is characterized by the Debye-Hückel length $1 / \kappa$, becomes smaller. This diffuse Debye cloud which dominates the electric anisotropy $\Delta \alpha_{\mathrm{el}}$ is polarized in electric fields and causes the orien tation of the particles [23]. We can demonstrate by determining the rotational diffusion constant that the PSS chains at minimum ionic strength 


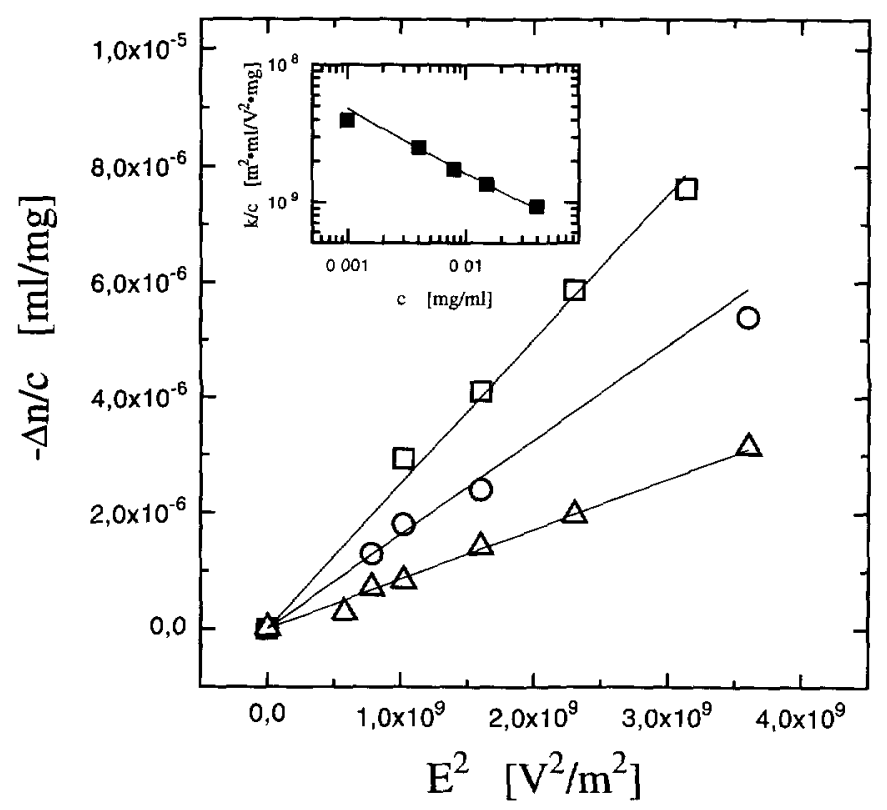

Fig. 2. - The negative electric birefringence signal of MW350 solutions with different concentrations $(c=0.001 \mathrm{mg} / \mathrm{ml}(\square), c=0.004 \mathrm{mg} / \mathrm{ml}(O)$ and $c=0.015 \mathrm{mg} / \mathrm{ml}(\Delta))$. The inlay shows the concentration dependence of the specific Kerr constant $\mathrm{k} / \mathrm{c}$ measured with rectangular square pulses. The values are fitted by a power law $k \propto c^{-1 / 2}$ (solid line)

and small concentrations $\left(<20 c^{*}\right.$, where $1 c^{*}=1$ particle $\left./ l_{\mathrm{c}}^{3}\right)$ are stretched and almost rigid [11]. As a consequence we observe a proportionality between the electric anisotropy $\Delta \alpha_{e l}$ and the Debye screening length $1 / \kappa$ (Fig. 3). $\Delta \alpha_{\text {el }}$ is calculated by using Equation (3a) and $1 / \kappa$ can be well approximated by $[23]$

$$
\frac{1}{\kappa} \approx \frac{11[\mathrm{~nm}]}{\sqrt{c[\mathrm{mg} / \mathrm{ml}]}} .
$$

Tricot and Houssier describe for comparable molecular weights a proportionality between $\Delta \alpha_{\mathrm{el}}$ and $c^{-1 / 2}$, too. However with raising concentration $\left(>20 c^{*}\right)$ our specific Kerr constant $k / c$ starts to decrease faster than $c^{-1 / 2}$ (Fig. 4).

This additional decrease is caused by a reducing persistence length $l_{\mathrm{p}}$ which is plotted in Figure 7. For the calculation of $l_{\mathrm{p}}$ we extrapolated the dependence of $\Delta \alpha_{\mathrm{el}}(c)$ (see Fig. 3) on concentrations which are larger than $0.1 \mathrm{mg} / \mathrm{ml} . \Delta \alpha_{0} / N$ and $k / c$ are already known by measuring the saturation value and the field strength dependence of the birefringence signal in the Kerr regime, respectively. The knowledge of all these parameters enables the calculation of $l_{\mathrm{p}}$. (Eq. (5a)). We have to admit that the determination of $\Delta \alpha_{\mathrm{el}}$ for intermediate concentrations $(0.1<c<1 \mathrm{mg} / \mathrm{ml})$ foots on an extrapolation of small concentrations. In order to avoid anomalous birefringence which is found for $c>20 c^{*}[11]$ we used $50 \mathrm{kHz}$ pulses.

4.2. Magnetic Birefringence. - The molecular weights MW350, MW780 and MW1132 are examined at different concentrations between 10 and $75 \mathrm{mg} / \mathrm{ml}$. Always the birefringence signal is proportional to the square of the external magnetic field (Fig. 5): we measure in the Cotton-Mouton regime. 


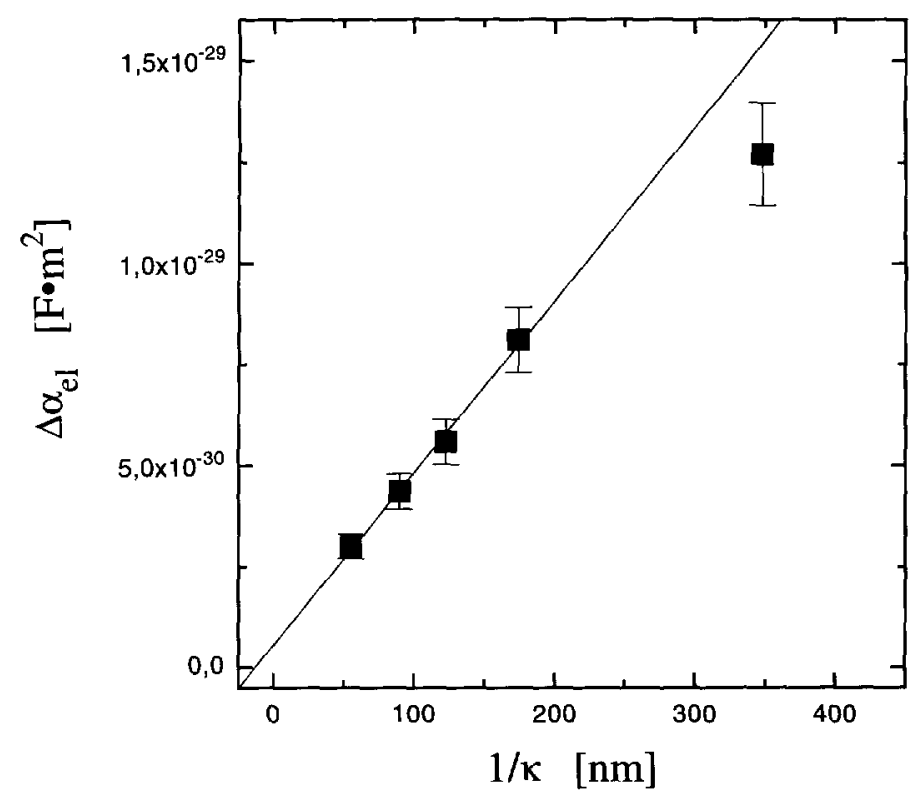

Fig. 3. - The electric polarization is plotted versus the Debye screening length $1 / \kappa$. The data points are calculated by using the values of the inlay of Figure 2 .

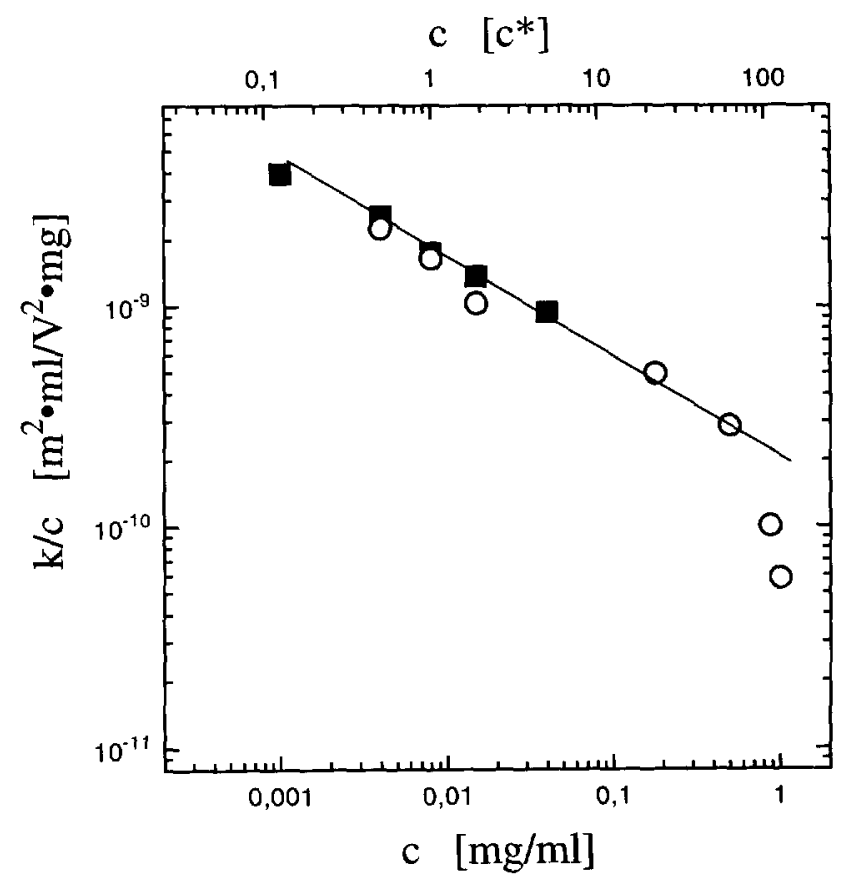

Fig. 4. - The specific Kerr constant at two frequencies $0 \mathrm{~Hz}(\mathbf{\square})$ and $50 \mathrm{kHz}(\mathrm{O})$. The data points represented by the solid squares are the same as in Figure 2 (inlay). 


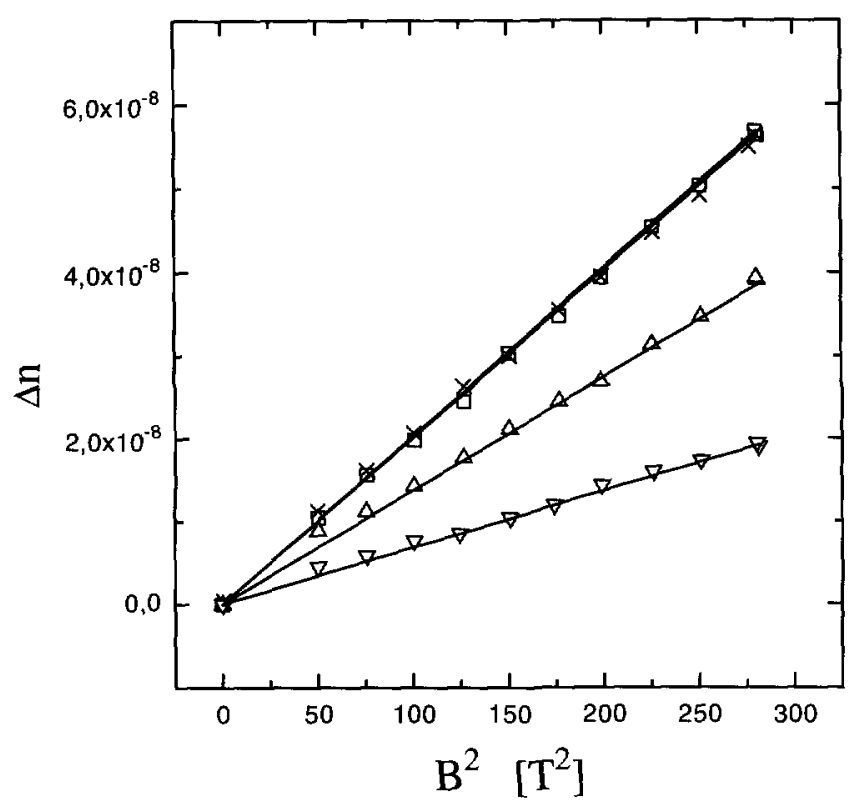

Fig. 5. - The magnetic birefringence as a function of the square of the magnetic field $(\square=$ MW350, $c=75 \mathrm{mg} / \mathrm{ml}, \times=M W 1132, c=75 \mathrm{mg} / \mathrm{ml} ; \Delta=\mathrm{MW350}, c=50 \mathrm{mg} / \mathrm{ml}$, all at minimum ionic strength; $\nabla=\mathrm{MW350,} c=50 \mathrm{mg} / \mathrm{ml}$ in $0.5 \mathrm{M} \mathrm{NaCl}$ ).

With rising the concentration the birefringence signal $\Delta n$ increases, while increasing the ionic strength by adding salt decreases the birefringence. At least the latter is observed in all comparable experiments [5,6] and is predicted for example by Odijk [7]. In contradiction to these results there are two recent publications by Joanny, Barrat, Witten and Pincus [24, 25] calculating a dependence of the persistence length on the salt concentration $c_{\mathrm{s}}$ like $c_{\mathrm{s}}^{+7 / 2}$ ! An increase of $l_{\mathrm{p}}$ would lead to an increase of the Cotton-Mouton constant (Eq. (5b)) and the magnetic birefringence signal. First measurements reveal the opposite.

In Figure 6 the Cotton-Mouton constants are plotted versus the particle concentration for different molecular weights and seem to be concentration independent for $c>25 \mathrm{mg} / \mathrm{ml}$. For small concentrations an increase can be observed which can be fitted with $C_{\mathrm{M}} \propto c^{-1 / 2}$.

Stevens and Kremer performed molecular dynamics simulations on multichain systems of flexible and charged chains [26]: Their model produces chain conformations changing from stretched (but with a finite persistence length) to coiled as the density of chains increases. Furthermore they find a vanishing molecular weight dependence for higher concentrations. Both the finiteness of $l_{\mathrm{p}}$ and the disappearance of the molecular weight dependence at higher particle concentration are observed by Degorgio et al. [27], too, but at a ionic strength which is about one order of magnitude larger than in our paper.

Weill and Maret examining very short chains describe a behavior which is similar to our results and conclude that the concentration and molecular weight independent value of the Cotton-Mouton constant $C_{\mathrm{M}}$ (for $c+c_{\mathrm{s}}>0.9 \mathrm{M}$ equivalent ionic strength, where $c_{\mathrm{s}}$ is the salt concentration) is related to the intrinsic part of the persistence length $l_{1}$ and the increase of $C_{\mathrm{M}}$ is an effect of a rising persistence length. In order to obtain the magnetic anisotropy $\Delta \chi$ they use the saturation value $\Delta n_{\text {sat }}$ of Kikuchi which is about $2 / 3$ of that of pure benzene. This value is explained by aromatic groups which are not strictly perpendicular to the polymer 


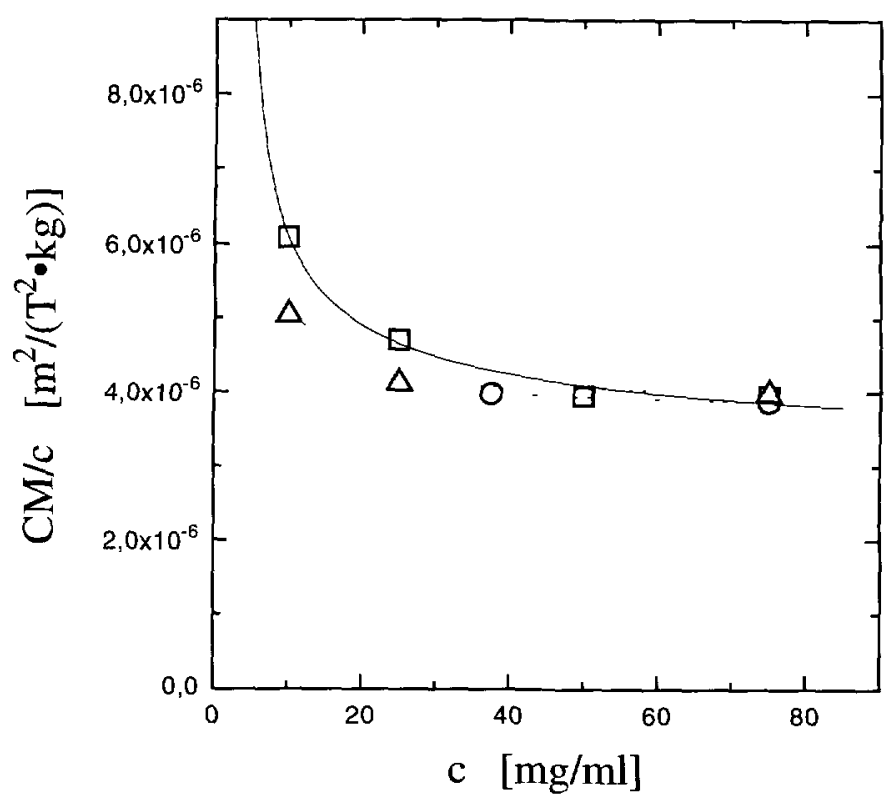

Fig 6. - The Cotton-Mouton constant for MW350 ( $\square$ ), MW780 (O) and MW1132 ( $\Delta$ ), all at minımum ionic strength The solid line corresponds to a fit. $C_{\mathrm{M}} \propto c^{-1 / 2}$.

length axis. Analogous they assume that the magnetic anisotropy $\Delta \chi$ of PSS is $2 / 3$ of that of benzene. We will use the same argumentation for calculating (Eq. (5b)) our persistence length, only using our (smaller) saturation value. The data of Weill and Maret are re-calculated with our saturation value and shown in Figure 7. For the first time the persistence length of PSS-chains at minımum ionic strength can be plotted for concentrations between 0.001 and 75 $\mathrm{mg} / \mathrm{ml}$.

Below $0.1 \mathrm{mg} / \mathrm{ml}$ we observe a nearly concentration independent persistence length $\left(l_{p} \approx 1200 \mathrm{~nm}\right)$, which is about twice the contour length of MW350 and characterizes elongated particles. This result has been obtained by static light scattering experiments and relaxation measurements of the birefringence signal after an applied rectangular pulse [11], too. The relaxation time $\tau$ can be calculated by

$$
\Delta n(t)=\Delta n \exp (-t / \tau)
$$

where $\Delta n(t)$ is the decay of the birefringence and $\Delta n$ is the already known steady state value For small concentrations $(c<0.1 \mathrm{mg} / \mathrm{ml})$ the relaxation time is comparable to that of rigid rods pointing out the stretched character of the PSS particles. This good accordance seems to justify both the use of equation (5) also for electric birefringence measurements and the extrapolation of $\Delta \alpha_{\mathrm{el}}$ and describes the transition between nearly stretched rods and distinct coiled chains in the intermediate concentration regime. However above $0.1 \mathrm{mg} / \mathrm{ml}\left(20 c^{*}\right)$ the relaxation time becomes smaller, the chains start to coil and behave like rigid but shorter rods with a new length with is about one third of the original length This coiling is also expressed by the decreasing persistence length $l_{\mathrm{p}}$ which is reduced down to a saturation value of $30 \mathrm{~nm}$ as shown in Figure 7 . The knowledge of $l_{p}$ enables the calculation of the mean square of the 
end-to-end distance $<h_{\text {of }}^{2}>[28]$ :

$$
<h_{\text {of }}^{2}>=2 l_{\mathrm{c}} l_{\mathrm{p}}
$$

The minimal end-to-end distance $\left(l_{\mathrm{c}}=424 \mathrm{~nm}, l_{\mathrm{p}}=30 \mathrm{~nm}\right)$ is about one third of the contour length $(120 \mathrm{~nm})$ in good accordance to the relaxation measurements. However one should mention that our minimum persistence length is about one order of magnitude larger than the intrinsic persistence length calculated by Odijk [7]:

$$
\begin{array}{ll}
l_{\mathrm{p}}=\frac{1}{4 Q \kappa^{2}}+l_{1} & \sigma \leq Q \\
l_{\mathrm{p}}=\frac{1}{4 \kappa^{2} \sigma^{2}}+l_{1} & \sigma>Q
\end{array}
$$

where $Q$ is the Bjerrum length (about $0.7 \mathrm{~nm}$ in water at $20^{\circ} \mathrm{C}$ ) and $s$ the mean distance of two neighbored charges assumed to be about the length of a monomeric unit $a=0.25 \mathrm{~nm}$. Therefore equation ( $9 \mathrm{a}$ ) has to be taken in order to calculate $l_{\mathrm{p}}$ which is additionally plotted in Figure 7. Obviously the values calculated by Odjik do not describe our results very well. More recent calculations by Le Bret et al. [29] lead to smaller persistence lengths, too. We assume that these differences are due to different ionic strengths: Our persistence length seems to be concentration independent for $c>50 \mathrm{mg} / \mathrm{ml}$ but it is still a function of the salt concentration. Therefore the persistence length of $30 \mathrm{~nm}$ is not the intrinsic one. We have to conclude that the calculation by Maret leading to persistence lengths which are only dependent on the sum of the (equivalent) particle and salt concentration is no longer valid for solutions at very low ionic

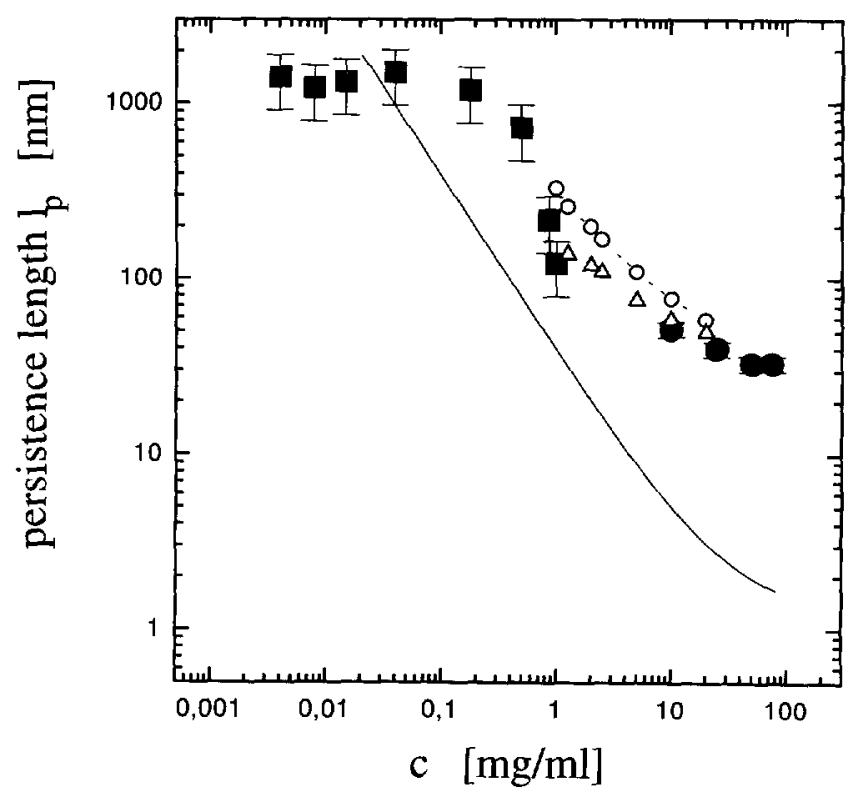

Fig. 7. - The persistence length of MW350 at minimum ionic strength determined by electric ( $\square$ ) and magnetic ( ) birefringence. Additionally the re-calculated persistence lengths (see text) obtained by Well and Maret are shown (MW $=15000 \mathrm{~g} / \mathrm{mol}(\Delta), M W=140000 \mathrm{~g} / \mathrm{mol}(\mathrm{o}))$. 
strength. Further experiments clarifying the influence of the ionic strength on the persistence length are in progress.

\section{Conclusion}

Electric and magnetic birefringence measurements were performed on aqueous solutions of poly(styrenesulfonate) with different molecular weights $\left(10^{5}<\mathrm{MW}<1.1 \times 10^{6} \mathrm{~g} / \mathrm{mol}\right)$ at minimum ionic strength. In an electric birefringence experiment we studied the saturation value of the birefringence signal. From the Kerr behavior of the birefringence at low electric field strengths the Kerr constant and the electric polarization $\Delta \alpha_{\mathrm{el}}$ are obtained over a wide concentration range $\left(5 \times 10^{-4}-5 \mathrm{mg} / \mathrm{ml}\right)$. For small concentrations $(c<0.1 \mathrm{mg} / \mathrm{ml})$ we find $\Delta \alpha_{\text {el }}$ and $k / c$ proportional to $c^{-1 / 2}$ and conclude that the chains are rigid and stretched. Above $0.1 \mathrm{mg} / \mathrm{ml}, k / c$ decreases faster than $c^{-1 / 2}$ indicating a coiling of the chains respectively a decrease of the persistence length which is calculated. In a magnetıc birefringence experiment we extend the concentration regime $(10<c<75 \mathrm{mg} / \mathrm{ml})$ in order to complete the determination of the persistence length at very high concentrations.

\section{Acknowledgments}

This work was supported by the Deutsche Forschungsgemeinschaft (Grant SFB 306). The magnetic experiments have been carried out in the High Magnetic Field Laboratory, Grenoble, and we are grateful for support given by the personnel.

\section{References}

[1] Krause R., Maier E. E, Deggelmann M., Hagenbuichle M., Schulz S. F. and Weber R., Physıca A 160 (1989) 135

[2] Hagenbuchle M, Weyerich B., Deggelmann M., Graf C., Krause R., Marer E. E, Schulz S. F., Klein R and Weber R., Physica A 169 (1990) 532.

[3] Graf C., Deggelmann M., Hagenbüchle M., Kramer H, Krause R., Martin C. and Weber R., J. Chem. Phys 95 (1991) 6284

[4] de Gennes P.-G, Scaling Concepts in Polymer Physics (Cornell University Press, Ithaca, NY, 1979).

[5] Well G and Maret G., Polymer Rep. 23 (1982) 1990.

[6] Krämer U and Hoffmann H., Macromolec 24 (1991) 256

[7] Odijk T, Macromolec. 12 (1979) 688.

[8] Kikuchi K. and Yoshioka K., J. Phys. Chem 77 (1973) 2101.

[9] Oppermann W, Macromol. Chem. 189 (1987) 927.

[10] Yamaola K. and Matsuda K., $J$ Phys. Chem. 89 (1985) 2779

[11] Johner C., Kramer H., Batzill S., Graf C , Hagenbüchle M., Martin C. and Weber R., J. Phys II France 4 (1994) 1571; Johner C., Untersuchungen an wảßrigen Suspensionen linearer Polyelektrolyte (Hartung-Gorre Verlag, Konstanz, ISBN 3-89191-885-2).

[12] Kramer H., Ph D. Thesıs, Universitat Konstanz, ISBN 3-89191-681-7.

[13] Trucot M. and Houssier C., Macromolec. 15 (1982) 854.

[14] Frederıcq E. and Houssier C, Electric Dicroism and Electrıc Birefringence (Clarendon Press, Oxford, UK, 1973). 
[15] Wilson R. W., Bropolymers 17 (1978) 1811.

[16] Maret G. and Well G., Biopolymers 22 (1983) 2727

[17] Deggelmann M., Palberg T., Hagenbuchle M, Maier E. E, Krause R, Graf C. and Weber R., $J$ Colloud Interface Scr. 143 (1991) 318

[18] Graf C., Kramer H., Deggelmann M., Hagenbuichle M., Johner C, Martin C. and Weber R, J. Chem Phys 98 (1993) 4920

[19] Kramer H., Deggelmann M., Graf C , Hagenbuchle M, Johner C and Weber R., Macromolec 25 (1992) 4325

[20] Maret G. and Dransfeld K., Topics in Applied Physics 57 (Sprnger Verlag Berlin, Heidelberg, New York, Tokyo, ISBN 3-540-13504-9).

[21] Oppermann W., Macromol. Chem. 189 (1988) 927.

[22] Kramer H, Graf C., Hagenbuchle M., Johner C., Martın C, Schwind P. and Weber R., J. Phys. II France 4 (1994) 1061.

[23] Schulz S. F , Ph. D Thesıs, Universitat Konstanz (1989)

[24] Barrat J -L and Joanny J -F., J. Phys. II France 4 (1994) 1089

[25] Witten T. A. and Pincus P. A , J. Phys. II France 4 (1994) 1103

[26] Stevens M. J and Kremer K., Phys Rev Lett. 71 (1992) 2228

[27] Degorg1o V., Mantegazza F. and Piazza R, Europhys Lett 15 (1991) 75

[28] Elias H.-G., Makromolekule (Huthig \& Wepf Verlag, Basel, Heldelberg).

[29] Le Bret M., J. Chem. Phys 76 (1982) 6243 